\section{Reverse Iontophoresis as a Noninvasive Tool for Lithium Monitoring and Pharmacokinetic Profiling}

\author{
Benoît Leboulanger, ${ }^{1,2}$ Marc Fathi, ${ }^{3}$ \\ Richard H. Guy, ${ }^{1,2}$ and \\ M. Begoña Delgado-Charro ${ }^{1,2,4}$
}

\section{Received December 16, 2003; accepted March 18, 2004}

Purpose. Transdermal iontophoresis was investigated as a noninvasive tool for drug monitoring and pharmacokinetic profiling. Lithium, a frequently monitored drug, was used as a model. The objectives were a) to demonstrate the linear dependence of the iontophoretic extraction flux of lithium on the subdermal concentration of the drug, b) to evaluate the capacity of iontophoresis to monitor sudden changes in the subdermal level, c) to investigate the utility of reverse iontophoresis as a tool in pharmacokinetic studies, and d) to examine the validity of an internal standard calibration procedure to render the method completely noninvasive.

Methods. Transdermal, iontophoretic extraction was performed in vitro using dermatomed pig-ear skin. The subdermal solution consisted of a physiological buffer containing lithium chloride at concentrations in the therapeutic range and two putative internal standards, sodium and potassium, at fixed physiological levels. The subdermal concentration of lithium was changed either in a stepwise fashion or by simulating one of two pharmacokinetic profiles.

Results. Lithium was extracted via electromigration to the cathode. A excellent correlation between subdermal lithium concentration and iontophoretic extraction flux was observed. Iontophoresis tracked sudden concentration changes and followed kinetic profiles. In addition, the effective elimination rate constant could be directly, and noninvasively, estimated from the extraction flux data.

Conclusions. Reverse iontophoresis is a potentially useful and noninvasive tool for lithium monitoring.

KEY WORDS: iontophoresis; lithium; reverse iontophoresis; therapeutic drug monitoring; transdermal extraction.

\section{INTRODUCTION}

Currently, therapeutic drug monitoring and pharmacokinetic studies depend principally upon the quantification of the

\footnotetext{
${ }^{1}$ School of Pharmacy, University of Geneva, CH-1211 Geneva 4, Switzerland.

${ }^{2}$ Centre International de Recherche et d'Enseignement ("Pharmapeptides"), F-74160 Archamps, France.

${ }^{3}$ Clinical Chemistry Central Laboratory, Geneva University Cantonal Hospital, CH-1211 Geneva 14, Switzerland.

${ }^{4}$ To whom correspondence should be addressed. (e-mail: begonia. delgado@pharm.unige.ch)

ABBREVIATIONS: J, extraction flux (units: $n$ mol/h); $\mathrm{R}_{\mathrm{I} . \mathrm{S} \text {, , ratio }}$ between lithium (Li) and internal standard (I.S.) extraction fluxes $\left(\mathrm{J}_{\mathrm{Li}} / \mathrm{J}_{\mathrm{ISS}}\right) ; \mathrm{C}_{\mathrm{Li}}$, lithium subdermal concentration (units: $\left.\mathrm{mM}\right) ; \gamma$, proportionality constant (units: $\mu \mathrm{l} / \mathrm{h}$ ) between $\mathrm{J}_{\mathrm{Li}}$ and $\mathrm{C}_{\mathrm{Li}} ; \gamma^{\#}$, propor-

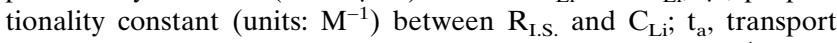
number of ion $\mathrm{a} ; \mathrm{K}_{\mathrm{e}}$, elimination rate constant (units: $\min ^{-1}$ ); $\mathrm{T}_{1 / 2}$, half-life $(\mathrm{min}) ; \mathrm{C}_{\mathrm{t}}$, concentration at a given time $\mathrm{t}(\mathrm{mM}) ; \mathrm{V}_{\mathrm{d}}$, volume of distribution $(\mathrm{ml}) ; \mathrm{Cl}$, clearance $(\mathrm{ml} / \mathrm{h})$.
}

molecule in one or more blood samples. The invasive nature of the procedure, the associated risks of infection, the need for trained personnel, and, for some populations (e.g., neonates), the technical difficulty, limit the frequency and complexity of these studies. As a result, drug kinetics in certain patient groups are poorly understood, and drug monitoring, in general, is performed much less often than it should.

There is a clear need, therefore, for the development of noninvasive techniques, which would be much better accepted by the patient and would offer the possibility of frequent and ambulatory self-monitoring $(1,2)$. Pediatric, neonatal, and geriatric patients, as well as the chronically and critically ill, would benefit most from the availability of such tools. For example, manic-depressive patients receiving chronic lithium therapy would profit from frequent monitoring that does not demand repeated visits to the hospital. These patients are carefully supervised because of a) the wide intersubject variability observed in dose requirement and tolerance to the drug, b) the very narrow therapeutic index, and c) a half-life that depends on kidney function, sodium intake, and age (3). Monitoring is initially performed to adjust the dose: daily, weekly and, finally, monthly evaluations are carried out during the first 6 months. Thereafter, lithium levels are checked at least every three months to detect drifts in concentration (4). The latter may be due to age, pregnancy, low salt diet, fever, infection, drug interactions, other medical problems, and/or poor compliance with the dosage regimen (4-6). At present, lithium monitoring requires blood sampling. Attempts to use either saliva or urine as alternative matrices have not been successful (3,7-9).

Reverse, transdermal iontophoresis has been proposed as an alternative technique for noninvasive monitoring (1015). Potential applications in clinical chemistry and therapeutic drug monitoring have been identified. Iontophoresis involves the application of a small electrical current $(<0.5$ $\mathrm{mA} / \mathrm{cm}^{2}$ ) to the skin $(16,17)$ and results in enhanced transport across the membrane via two possible mechanisms (18-20). The first, electromigration, only concerns ions, which carry the current through the skin toward the electrode of opposite polarity. Thus, in reverse iontophoresis, anions are extracted at the anode and cations (such as lithium) at the cathode (negative electrode). The ion flux is related to the intensity of current applied via equation 1 :

$$
\mathrm{J}_{\mathrm{a}}=\frac{\mathrm{I} \cdot \mathrm{t}_{\mathrm{a}}}{\mathrm{z}_{\mathrm{a}} \cdot \mathrm{F}}
$$

where, $\mathrm{J}_{\mathrm{a}}, \mathrm{t}_{\mathrm{a}}$, and $\mathrm{z}_{\mathrm{a}}$ are the flux, transport number, and valence, respectively, of the ion "a"; I is the intensity of current applied, and F is Faraday's constant. It has been shown that, in the presence of competing ions, the transport number (i.e., the percentage of the charge carried) of a given ion is proportionally related to its concentration in the donor solution (21). Thus, in reverse iontophoresis, it is expected that the flux of a given analyte should be related to its concentration in the subdermal fluid. The second mechanism of transport is electroosmosis, which is a convective solvent flow, in the anode-to-cathode direction, due to the fact that the skin has a net negative charge. This flow increases the transdermal transport of neutral (e.g., glucose) and zwitterionic species and supplements the electromigration of cations. It has also 
been shown that the electroosmotic transport of an analyte is directly proportional to the concentration of the species present in the solvent $(19,22)$.

The Glucowatch Biographer (Cygnus, Inc., Redwood City, CA, USA), which monitors blood sugar, is the only approved reverse iontophoretic system on the market (23). Before use, the device has to be calibrated via a conventional finger-stick so that the amount of electroosmotically extracted glucose (measured in situ by the appparatus), in a defined period of current passage, can be related to the corresponding blood level. At present, it is unknown whether iontophoretic devices relying on electromigrative extraction will also require a similar calibration; such would be the case, for example, if the transport number of a specific ion demonstrated a significant inter-individual variability in vivo.

In any case, the development of a noninvasive calibration procedure can clearly be identified as a sensible priority for future applications of reverse iontophoresis in drug monitoring, and, recently, the use of an "internal standard" approach has been proposed $(10,11,24)$. The procedure takes advantage of the fact that iontophoretic extraction is not specific. For example, in the case of lithium, several other cations will be simultaneously extracted at the cathode. If one of these ions, which may be referred to as the "internal standard," is present in the body at a relatively constant concentration, then its iontophoretic flux $\left(\mathrm{J}_{\text {I.S. }}\right)$ would be expected to be constant as well. It follows that the ratio of the extraction fluxes, $\mathrm{J}_{\mathrm{Li}} / \mathrm{J}_{\mathrm{I} . \mathrm{S}}$, should be directly proportional to the ratio of their respective concentrations $\left(\mathrm{C}_{\mathrm{Li}} / \mathrm{C}_{\mathrm{I} . \mathrm{S}}\right)(10,11,24)$. Given that $\mathrm{C}_{\mathrm{I} . \mathrm{S} \text {. }}$ is constant, $\mathrm{J}_{\mathrm{Li}} / \mathrm{J}_{\mathrm{I} . \mathrm{S}}$. becomes directly proportional to $\mathrm{C}_{\mathrm{Li}}$ :

$$
\mathrm{J}_{\mathrm{Li}} / \mathrm{J}_{\mathrm{I} . \mathrm{S} .}=\mathrm{R}_{\mathrm{I} . \mathrm{S} .}=\gamma^{\#} \cdot \mathrm{C}_{\mathrm{Li}}
$$

where $\gamma^{\#}$ is a constant. This hypothesis is tested here using sodium and potassium as candidate internal standards for lithium.

In summary, this work explores the potential of reverse iontophoresis as a noninvasive procedure for lithium monitoring and for pharmacokinetic profiling. In particular, the following questions have been addressed: i) Are iontophoretic extraction fluxes of lithium proportional to the corresponding subdermal concentrations? ii) Is iontophoresis capable of following sudden changes in the lithium subdermal concentration? iii) To what extent may reverse iontophoresis be useful for pharmacokinetic studies? iv) Does the "internal standard" calibration approach work?

\section{MATERIALS AND METHODS}

\section{Materials}

Eight molar $(8 \mathrm{M}) \mathrm{LiCl}$ solution, $\mathrm{NaCl}, \mathrm{KCl}, \mathrm{NaOH}$, $\mathrm{KOH}$, Hepes, Tris, TrisHCl, Mops, Ag wire 99.9\%, $\mathrm{AgCl}$ $99 \%$, and Pt $99.9 \%$ were purchased from Sigma-Aldrich (Saint Quentin Fallavier, France). Deionized water (resistivity $\geq 18.2 \mathrm{M} \Omega \cdot \mathrm{cm}$ ) was used to prepare all solutions.

\section{Skin Preparation}

Porcine ears were obtained fresh from the local slaughterhouse (S.O.D.E.X.A., Annecy, France) and were cleaned under cold running water. The whole skin was removed carefully from the outer region of the ear and separated from the underlying cartilage with a scalpel. Both full thickness and dermatomed $(\sim 750 \mu \mathrm{m})$ skin were used. The skin was wrapped individually in Parafilm and maintained at $-20^{\circ} \mathrm{C}$ for no longer than 2 months. All experiments were performed with 3 to 6 replicates, using skin samples originating from different pigs.

\section{Equipment}

Two types of iontophoretic cells were used: a) vertical iontophoretic cells (25) with an effective transport area of $0.78 \mathrm{~cm}^{2}$, a $6.5-\mathrm{ml}$ subdermal volume and 1-ml electrode chambers; and b) side-by-side three-compartment cells (11) with a $1-\mathrm{cm}^{2}$ skin surface area, a $4.54 \pm 0.15 \mathrm{ml}$ subdermal compartment, and 1.5-ml electrode chambers. Access ports to the subdermal compartment permitted the lithium concentration to be perfused at a fixed level, to be changed abruptly, and to be modulated continuously over time so as to mimic a pharmacokinetic profile. A manual power supply (either a KEPCO 1000M, Flushing, NY, USA, or a Yokogawa 7651, Tokyo, Japan) was used to deliver a constant current via $\mathrm{Ag} / \mathrm{AgCl}$ electrodes (26).

\section{Fixed-Concentration Extraction Experiments}

Full-thickness skin was clamped in vertical iontophoretic cells. First, the subdermal and anodal compartments were filled with a pH 7.4 buffer comprising $25 \mathrm{mM}$ Hepes and $133 \mathrm{mM} \mathrm{NaCl}$. The cathodal compartment was filled with a $\mathrm{pH} 7.4$ buffer comprising $25 \mathrm{mM}$ Hepes and $10 \mathrm{mM} \mathrm{KCl}$.

After $30 \mathrm{~min}$ equilibration, the anodal and cathodal solutions were refreshed. The subdermal chamber was filled with the "donor" solution, which consisted of the same buffer to which lithium chloride was added at one of three different concentrations $(0.6,1.0$, and $1.5 \mathrm{mM})$ corresponding to the drug's therapeutic range. Iontophoresis was performed for $5 \mathrm{~h}$ by applying a constant current of $0.4 \mathrm{~mA}$ via $\mathrm{Ag} / \mathrm{AgCl}$ electrodes. The current was stopped hourly to permit the collection and replacement of the entire electrode chambers solutions. Three replicates were made. The samples were assayed for lithium by graphite furnace atomic spectrometry (GFAS).

\section{Stepwise Concentration Change Experiments}

Dermatomed skin was clamped between the three compartments of side-by-side cells. During a 30-min equilibration period, the subdermal compartment was filled with $3.5 \mathrm{ml}$ of a pH 7.4 buffer solution containing $32 \mathrm{mM}$ Tris, $34 \mathrm{mM}$ Mops and $133 \mathrm{mM} \mathrm{NaCl}$. The anodal chamber was filled with a $\mathrm{pH}$ 7.4 buffer comprising $90 \mathrm{mM}$ Tris/Tris $\mathrm{HCl}$, whereas the cathodal chamber was also buffered at physiological $\mathrm{pH}$ with $32 \mathrm{mM}$ Tris and $34 \mathrm{mM}$ Mops. Subsequently, the anodal and cathodal solutions were refreshed. The subdermal chamber was filled with the same buffer to which $4 \mathrm{mM}$ potassium chloride and lithium chloride at either $0.95 \mathrm{mM}$ (first experiment) or $1.7 \mathrm{mM}$ (second experiment) were added. The concentration of $\mathrm{LiCl}$ in the subdermal donor solution was then changed in a stepwise fashion at 120 and $210 \mathrm{~min}$ : in the first experiment, to $2.7 \mathrm{mM}$ and $1.8 \mathrm{mM}$, respectively; in the second, to 0.6 and $1.1 \mathrm{mM}$.

Iontophoresis was performed for $5 \mathrm{~h}$ at a constant current of $0.4 \mathrm{~mA}$. Six replicates were carried out. Every $30 \mathrm{~min}$, the current was stopped and the entire electrode chamber 
solutions were sampled and refilled with fresh buffer. The samples were assayed for lithium by graphite furnace atomic spectrometry (GFAS) and for potassium and sodium by flame atomic absorption spectrometry (FAAS).

\section{Concentration-Profile Kinetic Experiments}

Dermatomed skin was clamped in side-by-side cells. After an equilibration period as described before, the solutions in the three compartments were refreshed. Then, the lithium content of the subdermal solution was varied to simulate the plasma concentration profile observed after either an IV bolus or a continuous infusion (see below). Iontophoresis was performed at a constant current of $0.4 \mathrm{~mA}$ for $5 \mathrm{~h}$. Every $30 \mathrm{~min}$, the current was stopped (for a period of $\sim 5 \mathrm{~min}$ ) to permit the collection and the replacement of the entire electrode solutions. At the midpoint of each of iontophoretic period, $10 \mu \mathrm{l}$ of the subdermal solution were sampled, and the actual concentrations of lithium, sodium and potassium therein were quantified by ionic chromatography with conductimetric detection, allowing their iontophoretic extraction fluxes to be calculated.

\section{Intravenous Bolus}

A syringe pump (Genie 8, Kent Scientific Corporation, Torrington CT, USA) infused the subdermal buffer ( $\mathrm{pH} 7.4$, $32 \mathrm{mM}$ Tris, $34 \mathrm{mM}$ Mops, $133 \mathrm{mM} \mathrm{NaCl}, 4 \mathrm{mM} \mathrm{KCl}$ ) at a rate of $1 \mathrm{ml} / \mathrm{h}$. After $1 \mathrm{~h}$ of iontophoresis, $6.2 \mu \mathrm{l}$ of a $0.8 \mathrm{M}$ aqueous solution of $\mathrm{LiCl}$ were directly added via a bolus injection into the subdermal compartment of each cell.

\section{Constant Rate Infusion}

A syringe pump infused the subdermal buffer as before, but at a rate of $4 \mathrm{ml} / \mathrm{h}$. After $1 \mathrm{~h}$ of iontophoresis, the composition of the infused solution was modified to incorporate $1.4 \mathrm{mM} \mathrm{LiCl}$.

\section{Analytical Techniques}

Graphite furnace atomic absorption spectrometry with Zeeman effect quantified lithium at $670.8 \mathrm{~nm}$ (Perkin Elmer 4100 ZL, Norwalk, CT, USA).

The samples were diluted 20 -fold in $0.2 \% \mathrm{HNO}_{3}$ before injection.

Flame atomic absorption spectrometry (Perkin Elmer AA Analyst 300, Perkin-Elmer Corporation) was used to measure sodium and potassium concentrations in iontophoretic and donor samples. The ions were quantified at $589.1 \mathrm{~nm}$ and $769.9 \mathrm{~nm}$, respectively, after a 10-fold dilution of the samples in $10 \% \mathrm{HNO}_{3}$.

Ionic chromatography was used to quantify lithium, sodium, and potassium. The Dionex DX-600 system (Voisins le Bretonneux, France) was equipped with a GP-50 pump and an AS-50 thermal compartment $\left(25^{\circ} \mathrm{C}\right)$. A $6 \mathrm{mM} \mathrm{H}_{2} \mathrm{SO}_{4}$ mobile phase was pumped $(1 \mathrm{ml} / \mathrm{min})$ through a $\mathrm{CS}-16$ cationic column. Detection involved a ED-50 detector and an Atlas suppressor $(61 \mathrm{~mA})$.

\section{Statistics}

Data analysis, linear and nonlinear regressions were performed with Graph Pad Prism V.4.0 (GraphPad Software Inc.
San Diego, CA, USA). All linear regressions shown in this work were significant $(\mathrm{p}<0.001)$. The data from each iontophoresis cell was individually fitted to the corresponding regression equation, and the "kinetic" values derived correspond to the average and standard deviation (SD) of 6 cells. Kruskal-Wallis and repeated measures ANOVA analysis were performed with SigmaStat V.2.03 (SPSS Science Software $\mathrm{GmbH}$, Erkrath, Germany). The statistical significance level was fixed at $\mathrm{p}<0.05$. (AUC) $)_{0 \rightarrow \mathrm{t}}$ was determined via the trapezoidal method (Prism V.4.); (AUC) t $\rightarrow \infty_{\infty}$ was calculated from the ratio of the last value measured to the elimination constant rate $(27)$.

\section{RESULTS AND DISCUSSION}

\section{Fixed-Concentration Extraction Experiments}

This first set of experiments verified the concentration dependence of the lithium iontophoretic extraction flux over the therapeutic range. Lithium was extracted at the cathode as expected. Figure 1 shows that lithium flux stabilized after approximately $2-3 \mathrm{~h}$ of iontophoresis. The delay results from the fact that, when the current is started, the most readily available charge carriers are the endogenous ions already present inside the skin (18); only after this "reservoir" is depleted can lithium assume its full role in transporting charge across the barrier. Lithium transport became steady after a few hours of iontophoresis, in a similar manner to that reported for acetate $(11)$, but more rapidly than valproate $(\sim 5$ h) (10) and phenytoin (>10 h) (11). The iontophoretic lithium flux, when the "donor" concentration was $0.6 \mathrm{mM}$, reached $20.0 \pm 1.0 \mathrm{nmol} \cdot \mathrm{h}^{-1}$, a value nearly an order of magnitude greater than that found for valproate $\left(2.3 \mathrm{nmol} \cdot \mathrm{h}^{-1}\right)$ under similar conditions (10). This illustrates the critical role of the physicochemical properties of the analyte of interest in determining the feasibility of iontophoretic extraction. Lithium, being smaller, more mobile and much less lipophilic than valproate, competes much better in carrying the charge across the skin. Furthermore, electroosmosis assists lithium transport while reducing that of the anionic valproate (19).

The relationship between lithium flux and subdermal concentration was analyzed by linear regression [Eq. (3)], and the results are in Table I:

$$
\mathrm{J}_{\mathrm{Li}}=\gamma \cdot \mathrm{C}_{\mathrm{Li}}
$$

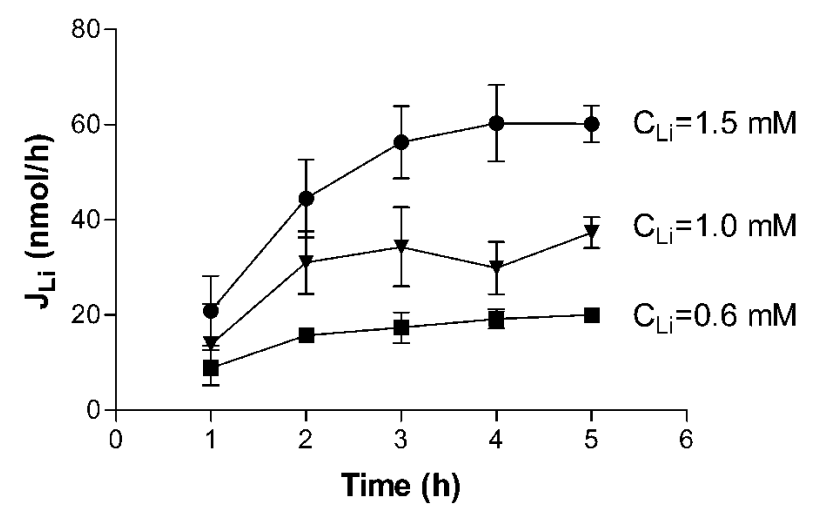

Fig. 1. Reverse iontophoretic extraction fluxes of lithium as a function of time and subdermal lithium concentration. Each data point represents the mean \pm standard deviation $(n=3)$. 
Table I. Linear Regressions of the Iontophoretic Extraction Fluxes of Lithium $\left(\mathrm{J}_{\mathrm{Li}}\right.$ in Units of $\left.\mathrm{nmol} / \mathrm{h}\right)$ as a Function of the Drug's Subdermal Concentration $\left(\mathrm{C}_{\mathrm{Li}}\right.$ in $\left.\mathrm{mM}\right)$ After Different Times of Iontophoresis (Data in Fig. 1), According to the Equation $\mathrm{J}_{\mathrm{Li}}=\gamma \cdot \mathrm{C}_{\mathrm{Li}}+$ Intercept* $^{*}$

\begin{tabular}{ccc}
\hline Time $(\mathrm{h})$ & $\gamma(\mu \mathrm{l} / \mathrm{h})$ & $\mathrm{r}^{2}$ \\
\hline 1 & $13 \pm 6$ & 0.43 \\
2 & $31 \pm 5$ & 0.85 \\
3 & $42 \pm 6$ & 0.89 \\
4 & $44 \pm 7$ & 0.87 \\
5 & $43 \pm 3$ & 0.97 \\
\hline
\end{tabular}

* The absolute values of the intercepts were $9 \mathrm{nmol} / \mathrm{h}$ or less.

The values of the slope $(\gamma)$ progressively increased until the third hour of extraction. Satisfactory correlation coefficients were observed as early as $2 \mathrm{~h}$ after the initiation of iontophoresis $\left(\mathrm{r}^{2}=0.85\right)$, with the best correlation obtained at $5 \mathrm{~h}$ $\left(r^{2}=0.97\right)$. Overall, this first experiment demonstrated that a linear relation between lithium extraction flux and the subdermal concentration of the drug is established after a relatively short sampling time.

\section{Stepwise Concentration Change Experiments}

The experiments began with an initial 2-h period of current passage, during which the lithium subdermal concentration was maintained constant at either $0.95 \mathrm{mM}$ or $1.7 \mathrm{mM}$ (Figs. 2a and 2b, respectively). During this time, the iontophoretic fluxes increased and reached steady values faster than observed before. This was probably due to the smaller thickness of the skin membrane used (dermatomed vs. fullthickness tissue) and the shorter sampling intervals used (30 min vs. $1 \mathrm{~h}$ ), which allowed the kinetics to be determined more precisely.

The concentration of $\mathrm{LiCl}$ in the subdermal solution was then changed in a stepwise fashion at 120 and $210 \mathrm{~min}$ : in the first experiment, to $2.7 \mathrm{mM}$ and $1.8 \mathrm{mM}$, respectively
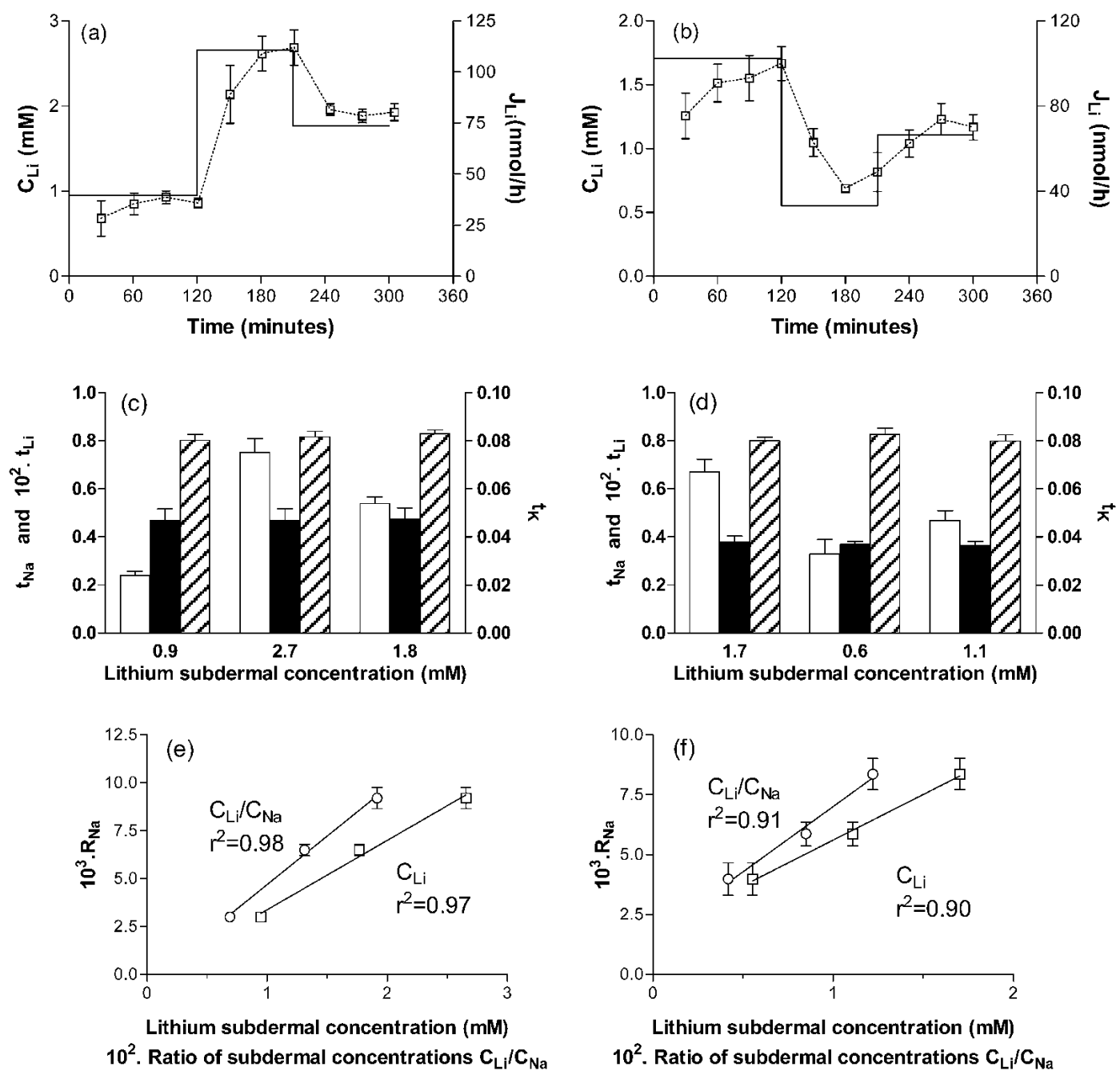

Fig. 2. Monitoring of lithium subdermal concentration changes: (a) first experiment, (b) second experiment. The continuous lines indicate the stepwise changes in the subdermal lithium concentrations. The open squares are the lithium iontophoretic fluxes. Each data point represents the mean \pm standard deviation $(n=6)$. Transport numbers of lithium ( $\mathrm{t}_{\mathrm{Li}}$, open bars) potassium ( $\mathrm{t}_{\mathrm{K}}$, solid bars), and sodium ( $\mathrm{t}_{\mathrm{Na}}$, hatched bars) determined from the iontophoretic fluxes in (c) the first experiment and (d) the second experiment. Linear regressions between the ratio of extraction fluxes $\left(\mathrm{R}_{\mathrm{Na}}\right)$ and either the lithium subdermal concentration or the ratio of subdermal concentrations $\left(\mathrm{C}_{\mathrm{Li}} / \mathrm{C}_{\mathrm{Na}}\right)$ determined using the data from (e) the first experiment and (f) the second experiment. 
(Fig. 2a); in the second, to 0.6 and $1.1 \mathrm{mM}$ (Fig. 2b). These sudden changes, which are much more abrupt than any possible in an in vivo situation of course, were carried out to test the responsiveness of reverse iontophoresis to such variations.

Figure 2 shows that iontophoresis was quite efficient in following the stepwise changes in the subdermal composition. Lithium fluxes responded appropriately to the new conditions established in each case and reached new steady values after a relatively short delay. As the "physiological" buffer used remained constant, increasing or decreasing the lithium concentration conferred, respectively, a better or worse chance for the drug to compete to carry the charge across the skin [i.e., to adopt a higher or smaller transport number (18)].

Taken together, the first two sets of experiments confirm that reverse iontophoresis of a highly mobile drug, such as lithium, can provide credible information about concentration changes occurring in the internal medium with a relatively short time-lag.

\section{Internal Standard Calibration}

As discussed before, the Glucowatch Biographer requires an initial calibration to be performed via a conventional ("finger-stick") blood measurement. Clearly, for therapeutic drug monitoring, an alternative, noninvasive calibration procedure is essential. We have, therefore, considered the use of an internal standard calibration [Eq. (2)] (10). Endogenous electrolytes, such as sodium and potassium, seemed, a priori, good candidates as internal standards for lithium reverse iontophoresis. First, these are cations, extracted at the cathode and, like lithium, principally by electromigration. Second, their physiological concentrations are normally quite constant, ranging from 135 to $143 \mathrm{mM}$ for sodium and between 3.3 and $4.6 \mathrm{mM}$ for potassium (28).

To test this idea, potassium and sodium extraction fluxes were also measured in the experiments discussed above. The essential requirement for the internal standard is that its extraction flux is independent of the target analyte concentration; in other words, that the transport number of the internal standard is constant and is not affected by variations in the analyte's subdermal level. Figures $2 \mathrm{c}$ and $2 \mathrm{~d}$ show the transport numbers of the three cations calculated using the $\mathrm{J}_{\mathrm{Li}}$ data in Figs. $2 \mathrm{a}$ and $2 \mathrm{~b}$ and the corresponding measured values of $\mathrm{J}_{\mathrm{Na}}$ and $\mathrm{J}_{\mathrm{K}}$. It is apparent that the sodium and potassium transport numbers were indeed constant within each experiment, while that of lithium varied in proportion to the drug's subdermal concentration.

This finding is completely logical for sodium, which is present subdermally at a much higher concentration than lithium. When lithium transports a slightly greater or smaller amount of charge, due to its subdermal level changing, sodium (as the major current carrier) is able to "take up the slack" without a significant impact on its transport number (18). On the other hand, for potassium, whose physiological concentration is much closer to lithium's therapeutic range, one might have expected some compensation between the transport numbers of the two cations. That this is not the case may be explained by the fact that potassium is, in some respects, a more "efficient" charge carrier than sodium; that is, while sodium is 30 times more concentrated than potassium in the subdermal solution, the ratio of their extraction fluxes was only $\sim 20$, meaning that potassium has the significantly higher mobility of the two ions. It is not simply concentration, therefore, which determines the absolute value of a transport number.

The next step was to verify the validity of Eq. (2). The regressions shown in Figs. 2e and $2 \mathrm{f}$ demonstrate the correlations between the ratio of lithium to sodium extraction fluxes $\left(\mathrm{R}_{\mathrm{Na}}\right)$ and either the lithium subdermal concentration, or the ratio of the subdermal concentrations of the two ions. When the corresponding regressions were performed for $R_{K}$, the correlations were satisfactory, though smaller $\left(\mathrm{r}^{2}=0.89\right.$ and 0.83 , respectively), presumably because of the slightly higher variability observed in potassium fluxes as compared to those of sodium. Nevertheless, overall, this component of the study demonstrated unequivocally that the internal standard concept works in vitro and may constitute a viable approach to normalize lithium iontophoretic extraction for drug monitoring purposes.

\section{Concentration-Profile Kinetic Experiments}

Further experiments examined whether transdermal iontophoresis could be used to determine pharmacokinetic parameters noninvasively. This was evaluated by simulating two classic plasma profiles in the subdermal compartment of the iontophoretic cells. It should be noted that the goal of these studies was to illustrate the versatility of reverse iontophoresis; there was no intention here to simulate "real" lithium pharmacokinetics, which can be complex $(4,29)$.

\section{Bolus}

The first kinetic profile considered was an IV bolus. The one-compartment model was characterized by an average volume of distribution of $4.54 \mathrm{ml}$ (the mean subdermal compartment volume of diffusion cells) and a clearance of $1 \mathrm{ml} / \mathrm{h}$ (the syringe pump rate of perfusion). The dose "injected" was $4.96 \mu$ moles. The subdermal concentration profile should therefore follow an exponential decay post-injection:

$$
\mathrm{C}_{\mathrm{t}}=\mathrm{C}_{0} \cdot \mathrm{e}^{-\mathrm{K}_{\mathrm{e}} \cdot \mathrm{t}}
$$

where $C_{t}$ and $C_{0}$ are the lithium subdermal concentration at a given time $t$ and at $t=0$, respectively, and $\mathrm{K}_{\mathrm{e}}$ is the elimination rate constant. Upon combination of i) Eqs. (3) and (4), and ii) Eqs. (2) and (4), two testable hypotheses were defined for this experiment, namely:

$$
\begin{aligned}
J_{L i} & =\gamma \cdot C_{0} \cdot e^{-K_{e} \cdot t} \\
R_{\text {I.S. }} & =\gamma^{\#} \cdot C_{0} \cdot e^{-K_{e} \cdot t}
\end{aligned}
$$

where the significance of $\mathrm{J}_{\mathrm{Li}}, \mathrm{R}_{\mathrm{I.S}}, \gamma$, and $\gamma^{\#}$ have been previously defined.

Throughout these experiments, sodium and potassium extraction fluxes were constant averaging $9.4 \mu \mathrm{mol} / \mathrm{h}( \pm 4 \%)$ and $0.55 \mu \mathrm{mol} / \mathrm{h}( \pm 11 \%)$, respectively. On the other hand, the lithium fluxes, in general, tracked the changes in its subdermal concentrations. Figure 3 shows the lithium subdermal concentration, the lithium extraction flux and the ratios of extraction fluxes $\left(\mathrm{J}_{\mathrm{Li}} / \mathrm{J}_{\mathrm{Na}}\right.$ and $\left.\mathrm{J}_{\mathrm{Li}} / \mathrm{J}_{\mathrm{K}}\right)$ as a function of time postinjection. In general, good agreement with the model is observed. The subdermal concentration data allowed the reference values for the parameters characterizing the model to 

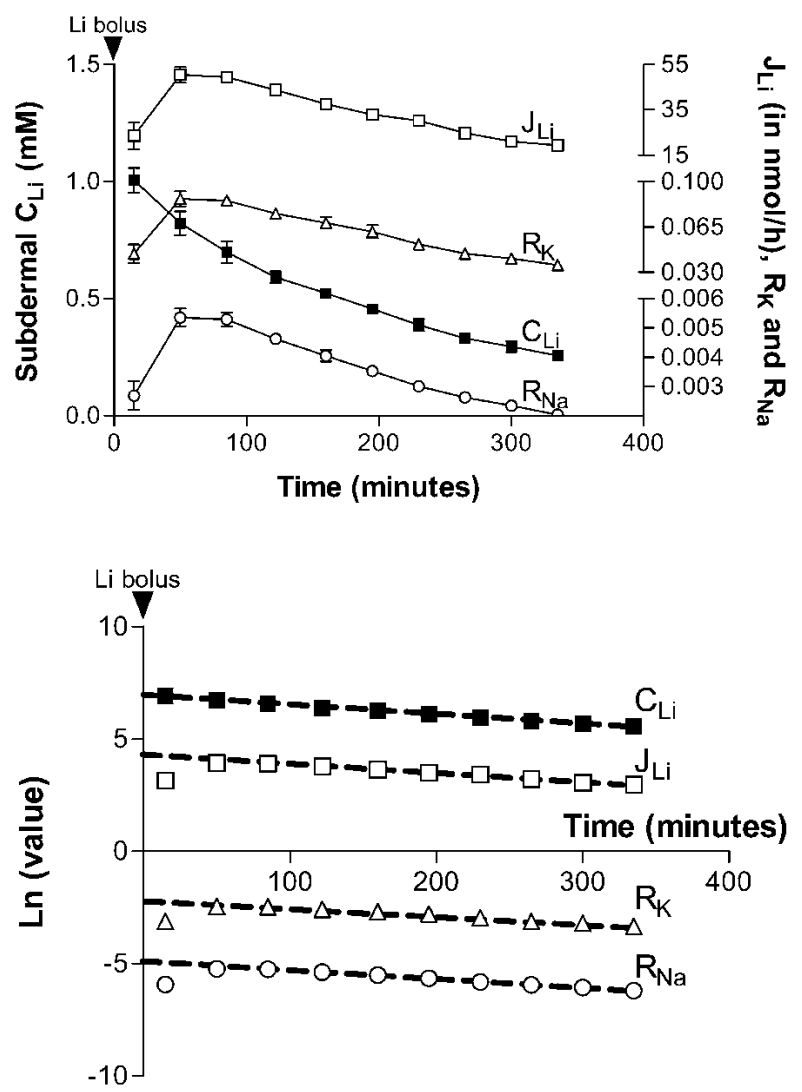

Fig. 3. Simulated lithium bolus administration (top panel) and a semi-logarithmic transformation of the data (bottom panel). The solid squares are the subdermal lithium concentrations; the open squares are the iontophoretic extraction fluxes of the drug $\left(\mathrm{J}_{\mathrm{Li}}\right)$. The open circles and open triangles are, respectively, the extraction flux ratios, $\mathrm{R}_{\mathrm{Na}}$ and $\mathrm{R}_{\mathrm{K}}$. Each data point represents the mean \pm standard deviation $(n=6)$. Solid lines of simple interpolation through the data are shown in the top panel; the dashed lines in the bottom panel, on the other hand, are linear regressions.

be determined (Table II). These experimental parameters agreed well with the theoretical values cited above.

Figure 3 reveals that the values of $\mathrm{J}_{\mathrm{Li}}, \mathrm{R}_{\mathrm{Na}}$, and $\mathrm{R}_{\mathrm{K}}$ do not conform to the expected profiles [Eqs. (5) and (6)] during the first hour of extraction. In fact, the profiles are reminiscent of an oral administration, for example, with a very fast absorption phase. After $1 \mathrm{~h}$, however, the three profiles decreased in parallel with the subdermal $\mathrm{Li}$ concentration. It appears therefore, that during the first hour, $\mathrm{J}_{\mathrm{Li}}, \mathrm{R}_{\mathrm{Na}}$, and $\mathrm{R}_{\mathrm{K}}$ reflect two concurrent processes: i) the subdermal lithium kinetics and ii) the establishment of steady iontophoresis extraction fluxes across the skin. That is, until $\gamma$ and $\gamma^{\#}$ become constant, the $\mathrm{J}_{\mathrm{Li}}, \mathrm{R}_{\mathrm{Na}}$, and $\mathrm{R}_{\mathrm{K}}$ profiles report on both processes. Once this is achieved, the extraction flux becomes directly and proportionally dependent on the subdermal concentration, and the slopes of the lines in Fig. 3 are parallel.

Figure 4 presents the values of $\gamma$ and $\gamma^{\#}$ as a function of time. A repeated measures ANOVA demonstrates that $\gamma$ and $\gamma^{\#}$ become constant from the third sampling period (after $85 \mathrm{~min}$ of iontophoresis). Mean values for $\gamma(68.8 \pm 1.7 \mu \mathrm{l} / \mathrm{h})$, $\gamma_{\mathrm{Na}}^{\#}\left(7.3 \pm 0.2 \mathrm{M}^{-1}\right)$, and $\gamma_{\mathrm{K}}{ }^{\#}\left(114.1 \pm 4.2 \mathrm{M}^{-1}\right)$ were determined by linear regression through the data obtained post $85 \mathrm{~min}$ of iontophoresis.

Linear regression of the semi-logarithmic data (after the third sampling period) in Fig. 3 permitted the elimination rate constant $\left(\mathrm{K}_{\mathrm{e}}\right)$ to be determined from the iontophoretic extraction data and compared to the reference value (Table II). In general, $\mathrm{K}_{\mathrm{e}}$ was slightly underestimated relative to that calculated from the decay of the subdermal concentrations. Nevertheless, overall, the agreement was really quite good. One possible source of the differences observed is the time required for the iontophoretic sampling. The data point at $85 \mathrm{~min}$, for example, reflects a moving average, so to speak, of the instantaneous values during the sampling period between 70 and $100 \mathrm{~min}$. On the other hand, the subdermal $\mathrm{C}_{\mathrm{Li}}$ was measured in a sample taken at exactly 85 min (i.e., the midpoint of the iontophoretic extraction period). An analogy may be drawn between measurements of urinary excretion rates and plasma concentrations. Clearly, when comparing kinetic parameters from the two types of measurement, the degree of error (difference) becomes greater as the sampling period increases. This fact has been recognized in the Glucowatch with which glycemia is now assessed every 10 min such that very close tracking of glucose levels is possible. In the end, analytical sensitivity is the determining factor-for lithium, with the assay sensitivity and precision presently possible, 5-10 min sampling intervals are feasible.

The iontophoretic extraction data were next used to estimate additional pharmacokinetic parameters [including the clearance $(\mathrm{Cl})$ and volume of distribution $\left.\left(\mathrm{V}_{\mathrm{d}}\right)\right]$. Equations (5) and (6) indicate that $\mathrm{C}_{0}$ can be found provided that $\gamma$ and $\gamma^{\#}$, respectively, are known. Knowing $\mathrm{C}_{0}$, it is then straightforward to assess $\mathrm{V}_{\mathrm{d}}\left(=\operatorname{dose} / \mathrm{C}_{0}\right)$ and $\mathrm{Cl}\left(=\mathrm{K}_{\mathrm{e}} \cdot \mathrm{V}_{\mathrm{d}}\right)$. The first step, therefore, was to identify the values of $\gamma$ and $\gamma^{\#}$ to be used. Figure 4 shows that these coefficients of proportionality become reasonably constant after about $1.5 \mathrm{~h}$ of ionto-

Table II. Pharmacokinetic Parameters Determined in the Bolus Experiment (Mean $\pm \mathrm{SD}, \mathrm{n}=6$ )

\begin{tabular}{lccccccc}
\hline & $\begin{array}{c}\mathrm{r}^{2} \\
\geq\end{array}$ & $\begin{array}{c}\mathrm{K}_{\mathrm{e}} \\
\left(\times 10^{-3} / \mathrm{min}^{-1}\right)\end{array}$ & $\begin{array}{c}\mathrm{T}_{1 / 2} \\
(\mathrm{~min})\end{array}$ & $\begin{array}{c}\mathrm{C}_{0}{ }^{*} \dagger \\
(\mathrm{mM})\end{array}$ & $\begin{array}{c}\mathrm{Vd}^{*}, \dagger \\
(\mathrm{ml})\end{array}$ & $\begin{array}{c}\mathrm{Cl}^{*}, \dagger \\
(\mathrm{ml} / \mathrm{h})\end{array}$ & $\begin{array}{c}\mathrm{Cl}^{*}, \\
(\mathrm{ml} / \mathrm{h})\end{array}$ \\
\hline $\mathrm{C}_{\mathrm{Li} \text { Subdermal }}$ & 0.99 & $4.2 \pm 0.3$ & $168 \pm 14$ & $1.01 \pm 0.06$ & $4.9 \pm 0.3$ & $1.22 \pm 0.05$ & $1.21 \pm 0.04$ \\
$\mathrm{~J}_{\mathrm{Li}}$ & 0.99 & $3.9 \pm 0.2$ & $180 \pm 10$ & $0.99 \pm 0.06$ & $5.0 \pm 0.3$ & $1.17 \pm 0.02$ & $1.21 \pm 0.03$ \\
$\mathrm{R}_{\mathrm{K}}$ & 0.96 & $3.6 \pm 0.3 \S$ & $193 \pm 15 \S$ & $0.97 \pm 0.06$ & $5.1 \pm 0.3$ & $1.10 \pm 0.07 \S$ & $1.21 \pm 0.09$ \\
$\mathrm{R}_{\mathrm{Na}}$ & 1.00 & $3.8 \pm 0.2$ & $181 \pm 9$ & $0.98 \pm 0.06$ & $5.1 \pm 0.3$ & $1.17 \pm 0.04$ & $1.22 \pm 0.06$ \\
\hline
\end{tabular}

* Values determined using $\gamma, \gamma_{\kappa}^{*}$, or $\gamma,{ }_{\mathrm{Na}}{ }^{\#}$, respectively.

$\dagger$ Calculated assuming a one-compartment model: $\mathrm{V}_{\mathrm{d}}=$ dose $/ \mathrm{C}_{0}, \mathrm{Cl}=\mathrm{K}_{\mathrm{e}} \cdot \mathrm{V}_{\mathrm{d}}$.

$\$$ Model independent calculation using the corresponding area-under-the-curve.

$\S$ Value significantly different from reference value obtained from the direct measurements of $\mathrm{C}_{\mathrm{Li}}(\mathrm{p}<$ 0.05) (Kruskal-Wallis ANOVA on ranks). 


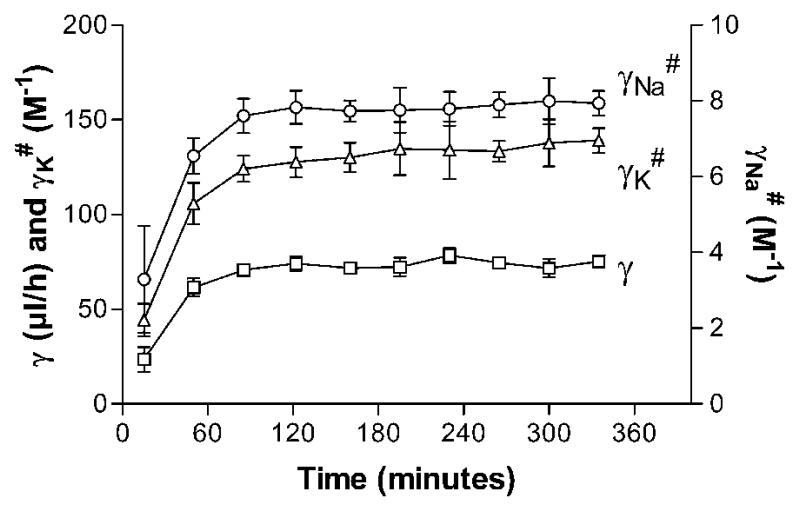

Fig. 4. Proportionality constants $\gamma$ and $\gamma^{\#}$ [defined in Eqs. (3) and (2), respectively, and determined from the bolus experiment] vs. time. Each data point represents the mean \pm standard deviation $(n=6)$.

phoresis, and the mean values from this point on are the logical choices for the determination of the pharmacokinetic parameters of interest (Table II). The $\mathrm{V}_{\mathrm{d}}$ and $\mathrm{Cl}$ determined in this way are quite close to the reference values. Though this type of calculation based on in vitro data is usefully illustrative, it remains to be seen in vivo the extent to which $\gamma$ and/or $\gamma^{\#}$ vary within and between subjects; that is, will it be necessary to determine $\gamma$ and/or $\gamma^{\#}$ for every patient or will a population average be sufficiently precise for all subjects? In the former ease, of course, careful calibration with blood sampling would be necessary for each person in order to define the value of the constant(s) to be used.

Self-evidently, the internal standard calibration approach leading to the deduction of $\gamma^{\#}$ is envisaged as a means to completely avoid calibration with blood sample. The constancy of $\mathrm{Na}^{+}$extraction in this work speaks to its considerable potential in this regard; on the other hand, potassium, which was also evaluated, yielded more variable results. Certainly with $\mathrm{Na}^{+}$, then, the approach could be useful for a therapeutic monitoring application during lithium therapy. Care is necessary with respect to the kinetics, however, as a finite time is required before $\gamma$ and $\gamma^{\#}$ reach stable values (Fig. 4). Whether this delay is partly an artefact, caused by the experimental design in which $\mathrm{Na}^{+}$and $\mathrm{K}^{+}$extraction fluxes were stabilized before Li was "injected" into the subdermal solution, remains to be seen. In a recent study (10) examining the idea of valproate monitoring by reverse iontophoresis, and using glutamate as an internal standard, the value of $\gamma^{\#}$ was constant from the very first sampling period, even though the extraction fluxes had not stabilized by this time. It is important to note, in this case, that the two ions were introduced simultaneously into the subdermal compartment. It follows that, for a patient receiving chronic lithium therapy, it is reasonable to expect $\gamma^{\#}$ to become constant more rapidly than that observed in the in vitro work presented here.

\section{Constant Rate Infusion}

The second situation considered was a constant infusion ( $5.6 \mu \mathrm{moles} / \mathrm{h})$ of lithium chloride into the subdermal compartment having $\mathrm{V}_{\mathrm{d}} \sim 4.54 \mathrm{ml}$. The clearance was $4 \mathrm{ml} / \mathrm{h}$. The drug concentration profile, in this case, is described by Eq. (7) $(27,30)$ :

$$
\mathrm{C}_{\mathrm{t}}=\mathrm{C}_{\mathrm{ss}}\left(1-\mathrm{e}^{-\mathrm{Ke} \cdot \mathrm{t}}\right)=\frac{\mathrm{K}_{0}}{\mathrm{~K}_{\mathrm{e}} \cdot \mathrm{V}_{\mathrm{d}}}\left(1-\mathrm{e}^{-\mathrm{Ke} \cdot \mathrm{t}}\right)
$$

which predicts that $C_{L i}$ will increase exponentially to a steadystate plateau, $\mathrm{C}_{\mathrm{ss}}$. Figure 5 shows that this plateau level $(\sim 1.3 \mathrm{mM})$ was attained after $3-3.5 \mathrm{~h}$ of perfusion. When the subdermal concentration profile was fitted to equation 7 ( $\mathrm{r}^{2} \geq 0.94$, nonlinear regression), the following reference values were obtained; $\mathrm{K}_{\mathrm{e}}=0.014 \pm 0.001 \mathrm{~min}^{-1} ; \mathrm{T}_{1 / 2}=50 \pm 4 \mathrm{~min}$; $\mathrm{C}_{\mathrm{ss}}=1.32 \pm 0.03 \mathrm{mM} ; \mathrm{V}_{\mathrm{d}}=5.1 \pm 0.3 \mathrm{ml} ;$ and $\mathrm{Cl}=4.2 \pm 0.1$ $\mathrm{ml} / \mathrm{h}$.

Figure 5 also demonstrates that the iontophoretic extraction of $\mathrm{Li}$ flux and the extraction flux ratios $\left(\mathrm{R}_{\mathrm{Na}}\right.$ and $\left.\mathrm{R}_{\mathrm{K}}\right)$ also increased exponentially toward steady-state values, conforming to the following equations, which result from the substitution of Eqs. (3) and (2), respectively, into Eq. (7):

$$
\begin{aligned}
& \mathrm{J}_{\mathrm{t}}=\mathrm{J}_{\mathrm{ss}} \cdot\left(1-\mathrm{e}^{-\mathrm{K}_{\mathrm{e}} \cdot \mathrm{t}}\right)=\gamma \cdot \mathrm{C}_{\mathrm{ss}} \cdot\left(1-\mathrm{e}^{-\mathrm{K}_{\mathrm{e}} \cdot \mathrm{t}}\right) \\
& \mathrm{R}_{\mathrm{t}}=\mathrm{R}_{\mathrm{ss}} \cdot\left(1-\mathrm{e}^{-\mathrm{K}_{\mathrm{e}} \cdot \mathrm{t}}\right)=\gamma^{\#} \cdot \mathrm{C}_{\mathrm{ss}} \cdot\left(1-\mathrm{e}^{-\mathrm{K}_{\mathrm{e}} \cdot \mathrm{t}}\right)
\end{aligned}
$$

The significance of $\mathrm{J}_{\mathrm{Li}}, \mathrm{R}_{\mathrm{I} . \mathrm{S}}, \gamma$, and $\gamma^{\#}$ are as before; $\mathrm{J}_{\mathrm{Ss}}$ and $R_{s s}$ represent the steady-state values of $J_{L i}$ and $R_{I . S}$, respectively.

Interpretation and analysis of the iontophoretic extraction flux data were more complicated than the IV bolus case. In the latter situation, the only "pharmacokinetic" process taking place in the subdermal compartment is drug elimination. In contrast, in the infusion scenario, there is both "input" and elimination; it should be recalled, furthermore, that the time to steady-state under these circumstances is on the order of four elimination half-lives. Again, because of these concurrent processes, the model described by Eqs. (8) and (9) fits the results very well after about $1 \mathrm{~h}$ (when the two first samples are omitted). The evolution of $\gamma$ and $\gamma^{\#}$ with time is shown in Fig. 6. It is first noted that the absolute values of these parameters are very similar to those observed in the I.V. bolus experiments (Fig. 4), supporting the contention that these proportionality constants may show very small interindividual differences. However, it takes longer (2.5-3 h) for the values of $\gamma$ and $\gamma^{\#}$ to stabilize in the infusion situation (repeated measures ANOVA). At this point, it was deduced

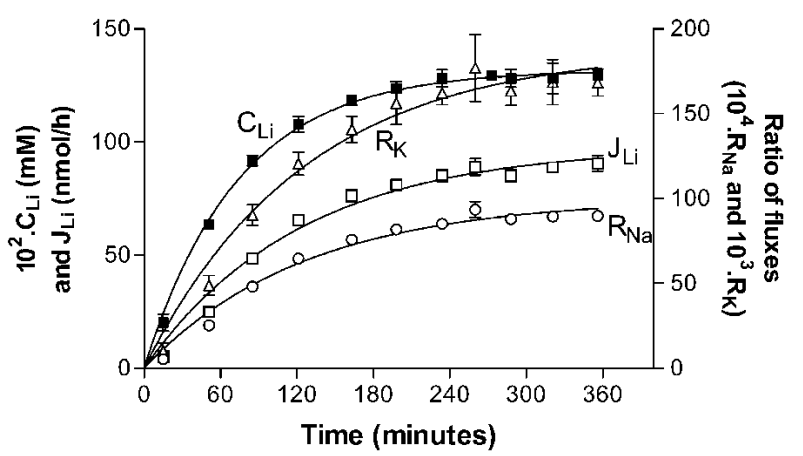

Fig. 5. Iontophoretic monitoring of lithium during a simulated constant infusion to steady-state. The subdermal lithium concentration profile is represented by the solid squares, and the line through the data is a fitted curve according to Eq. (7); the open squares are the iontophoretic extraction fluxes of the drug $\left(\mathrm{J}_{\mathrm{Li}}\right)$ [data fitted to Eq. (8)]. The open circles and open triangles are, respectively, the extraction flux ratios, $R_{\mathrm{Na}}$ and $\mathrm{R}_{\mathrm{K}}$ [results fitted using Eq. (9)]. Each data point represents the mean \pm standard deviation $(n=6)$. 


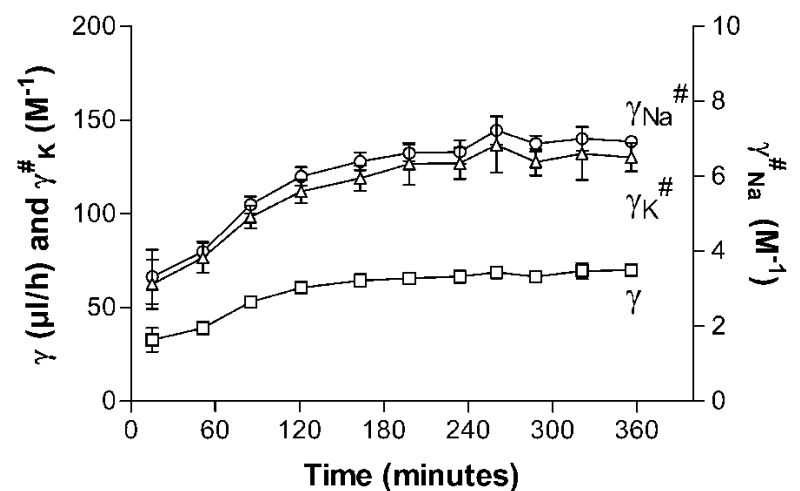

Fig. 6. Proportionality constants $\gamma$ and $\gamma^{\#}$ [defined in Eqs. (3) and (2), respectively, and determined from the constant infusion experiment] vs. time. Each data point represents the mean \pm standard deviation $(\mathrm{n}=6)$.

that $\gamma=65 \pm 14 \mu \mathrm{l} / \mathrm{h}, \gamma_{\mathrm{K}}{ }^{\#}=135 \pm 43 \mathrm{M}^{-1}$, and $\gamma_{\mathrm{Na}}{ }^{\#}=7.6$ $\pm 1.4 \mathrm{M}^{-1}$. It is logical to suppose that the increased time for stabilization is due to the fact that steady-state kinetics are approached slowly in the experimental infusion model here tested.

Thus, iontophoretic extraction fluxes become progressively more reflective of the subdermal kinetics with increasing time. When the iontophoretic data in Fig. 5 are fitted to Eqs. (8) and (9), the values of $J_{s s}$, and $R_{s s}$ are very close either to the experimental results or to the theoretical value. Similarly, the derived values for clearance were $4.1 \pm 0.1$ (from $\left.\mathrm{J}_{\mathrm{Li}}\right), 4.1 \pm 0.2\left(\right.$ from $\mathrm{R}_{\mathrm{Na}}$ ) and $4.1 \pm 0.1 \mathrm{ml} /$ hour $\left(\right.$ from $\mathrm{R}_{\mathrm{K}}$ ) which are in excellent agreement with the reference value of $4.2 \pm 0.1 \mathrm{ml} / \mathrm{h}$.

Estimation of $\mathrm{K}_{\mathrm{e}}$ from the iontophoretic extraction data was more challenging. This parameter was obviously underestimated when data from the earliest sampling times were included (Fig. 7). When these initial results were omitted, the fitting procedure improved $\left(r^{2} \geq 0.8\right)$; for example, analysis of data from $85 \mathrm{~min}$ onward resulted in values of $\mathrm{K}_{\mathrm{e}}\left(\right.$ in $\mathrm{min}^{-1}$ ) of $0.0095 \pm 0.0003\left(\right.$ from $\mathrm{J}_{\mathrm{Li}}$ ), $0.0091 \pm 0.0009$ (from $\mathrm{R}_{\mathrm{K}}$ ), and

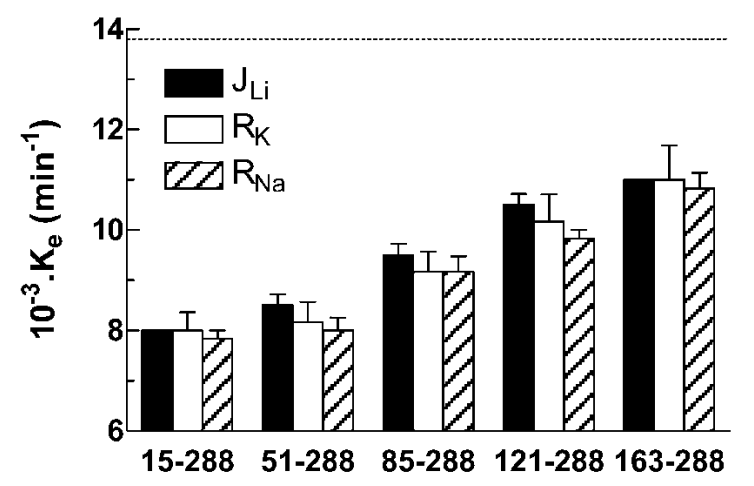

Time interval (minutes)

Fig. 7. Values of $\mathrm{K}_{\mathrm{e}}$ (mean $\pm \mathrm{SD} ; \mathrm{n}=6$ ) determined from the constant infusion experiment. Data for $\mathrm{J}_{\mathrm{Li}}, \mathrm{R}_{\mathrm{Na}}$, and $\mathrm{R}_{\mathrm{K}}$ (filled, open, and hatched bars, respectively) were fitted to Eqs. (8) and (9). The results were calculated from the individual data obtained during the different time intervals indicated on the abscissa. The dashed line at $\mathrm{K}_{\mathrm{e}}=0.014 \mathrm{~min}^{-1}$ indicates the "reference" value of this parameter.
$0.0091 \pm 0.0005$ (from $R_{\mathrm{Na}}$ ). The "reference" value, it is recalled, was $0.014 \mathrm{~min}^{-1}$. Thereafter, if results only from the latter half of the experiment are fitted (Fig. 7), the resulting $\mathrm{K}_{\mathrm{e}}$ increased somewhat but not significantly, and the goodness-of-fit decreased. It is not clear whether, in this experiment, the iontophoretic fluxes could ever provide a better estimation of $\mathrm{K}_{\mathrm{e}}$. Once steady-state is achieved, of course, the sensitivity of the model to determine $\mathrm{K}_{\mathrm{e}}$ is lost. It follows that there is a temporal "window of opportunity" for the estimation of $\mathrm{K}_{\mathrm{e}}$; long enough has to have elapsed so that the extraction fluxes have caught up with the subdermal kinetics, but not so long that steady-state is close to having been attained. On the other hand, the results demonstrate an effective means with which to determine noninvasively, and quite accurately, a drug's clearance.

In conclusion, the results presented here demonstrates that reverse iontophoretic monitoring of lithium is concentration-dependent, and that quantitative information about the drug's subdermal level can be obtained without a "blood" measurement via the use of $\mathrm{Na}^{+}$and/or $\mathrm{K}^{+}$as an "internal standard". The iontophoretic extraction flux of $\mathrm{Li}$, and the ratio of this flux to that of either $\mathrm{Na}^{+}$or $\mathrm{K}^{+}$, tracks pharmacokinetic changes in the drug's subdermal concentration rapidly and faithfully, allowing the remarkably noninvasive determination of certain pharmacokinetic parameters that are presently available only via plasma or whole blood measurements.

\section{ACKNOWLEDGMENTS}

We thank P. Bonnabry and H. Ing at the Central Pharmacy of the Geneva University Cantonal Hospital for making available the flame atomic absorption spectrometry apparatus. This research was supported by the Swiss National Research Foundation (3200-059042.99/1) and by the U.S. National Institutes of Health (EB-001420).

\section{REFERENCES}

1. B. Bailey, J. Klein, and G. Koren. Noninvasive methods for drug measurement in pediatrics. Pediatr. Clin. North Am. 44:15-26 (1997).

2. L. J. Rice. Needle phobia. An anesthesiologist's perspective. J. Peadiatr. 122:S9-S13 (1993).

3. A. Amdisen. Serum concentration and clinical supervision in monitoring of lithium treatment. Ther. Drug Monit. 2:73-83 (1980).

4. A. Amdisen. Serum level monitoring and clinical pharmacokinetics of lithium. Clin. Pharmacokinet. 2:73-92 (1977).

5. R. F. Kehoe. Monitoring lithium treatment. BMJ 306:269-270 (1993).

6. M. Schou. Lithium treatment during pregnancy, delivery, and lactation: an update. J. Clin. Psychiatry 51:410-413 (1990).

7. S. Pichini, I. Altieri, P. Zuccaro, and R. Pacifici. Drug monitoring in nonconventional biological fluids and matrices. Clin. Pharmacokinet. 30:211-228 (1996).

8. J. P. Moody. Biologic variation of serum and salivary lithium. Ther. Drug Monit. 21:97-101 (1999).

9. R. Obach, J. Borja, J. Prunonosa, J. M. Valles, J. Torrent, I. Izquierdo, and F. Jane. Lack of correlation between lithium pharmacokinetic parameters obtained from plasma and saliva. Ther. Drug Monit. 10:265-268 (1988).

10. M. B. Delgado-Charro and R. H. Guy. Transdermal reverse iontophoresis of valproate: a non-invasive method for therapeutic drug monitoring. Pharm. Res. 20:1508-1513 (2003).

11. B. Leboulanger, R. H. Guy, and M. B. Delgado-Charro. Reverse iontophoretic monitoring of free phenytoin. Ther. Drug Monit. 25:499 (2003). 
12. V. Merino, A. Lopez, D. Hochstrasser, and R. H. Guy. Noninvasive sampling of phenylalanine by reverse iontophoresis. J. Control. Rel. 61:65-69 (1999).

13. G. Rao, P. Glikfeld, and R. H. Guy. Reverse iontophoresis: development of a non invasive approach for glucose monitoring. Pharm. Res. 10:1751-1755 (1993).

14. J. A. Tamada, N. J. V. Bohannon, and R. O. Potts. Measurement of glucose in diabetic subjects using noninvasive transdermal extraction. Nat. Med. 1:1198-1201 (1995).

15. M. J. Tierney, J. A. Tamada, R. O. Potts, R. C. Eastman, K. Pitzer, N. R. Ackerman, and S. J. Fermi. The GlucoWatch ${ }^{\circledR}$ biographer: a frequent automatic and noninvasive glucose monitor. Ann. Med. 32:632-641 (2000).

16. R. R. Burnette. Iontophoresis. In J. Hadgraft and R. H. Guy (eds.), Transdermal Drug Delivery, Marcel Dekker, New York, 1989, pp. 247-291.

17. P. W. Ledger. Skin biological issues in electrically enhanced transdermal delivery. Adv. Drug Deliv. Rev. 9:289-307 (1992).

18. J. B. Phipps and J. R. Gyory. Transdermal ion migration. $A d v$. Drug Deliv. Rev. 9:137-176 (1992).

19. M. J. Pikal. The role of electroosmotic flow in transdermal iontophoresis. Adv. Drug Deliv. Rev. 9:201-237 (1992).

20. B. Leboulanger and R. H. Guy. and M. B. Delgado-Charro Reverse iontophoresis for non-invasive transdermal monitoring. Physiol. Meas. 25:R35-R50 (2003).

21. D. Marro, Y. N. Kalia, M. B. Delgado-Charro, and R. H. Guy.
Contributions of electromigration and electroosmosis to iontophoretic drug delivery. Pharm. Res. 18:1701-1708 (2001).

22. R. R. Burnette and B. Ongpipattanakul. Characterization of the permselective properties of excised human skin during iontophoresis. J. Pharm. Sci. 76:765-773 (1987).

23. R. O. Potts, J. A. Tamada, and M. J. Tierney. Glucose monitoring by reverse iontophoresis. Diabetes Metab. Res. Rev. 18:S49-S53 (2002).

24. A. Sieg, R. H. Guy, and M. B. Delgado-Charro. Reverse iontophoresis for non-invasive glucose monitoring: the internal standard concept. J. Pharm. Sci. 92:2295-2302 (2003).

25. P. Glikfeld, C. Cullander, R. S. Hinz, and R. H. Guy. A new system for in vitro studies of iontophoresis. Pharm. Res. 5:443446 (1988).

26. P. G. Green, R. S. Hinz, C. Cullander, G. Yamane, and R. H. Guy. Iontophoretic delivery of amino acids and amino acid derivatives across the skin in vitro. Pharm. Res. 8:1113-1120 (1991).

27. G. Houin. Pharmacocinétique, Edition Marketing, Paris, France, 1990.

28. R. J. Flanagan. Guidelines for the interpretation of analytical toxicology results and unit of measurement conversion factors. Ann. Clin. Biochem. 35:261-267 (1998).

29. M. E. Winter. Lithium. In M. E. Winter (ed), Basic clinical pharmacokinetics, Applied Therapeutics, Vancouver, WA, USA, 1994, pp. 257-265.

30. M. E. Winter. Basic Clinical Pharmacokinetics, Applied Therapeutics, Vancouver, WA, USA, 1994. 